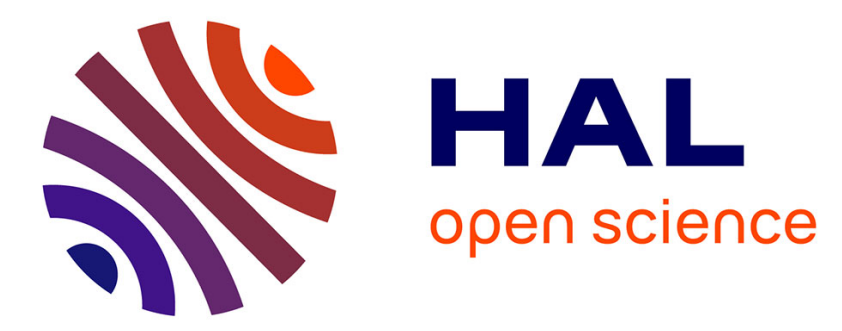

\title{
Health Regulatory Focus, Selection Optimization and Compensation Strategy and Sports Practice: A Mediational Analysis
}

\author{
Manon Laroche, Peggy Roussel, Nicolas Mascret, Francois Cury
}

\section{- To cite this version:}

Manon Laroche, Peggy Roussel, Nicolas Mascret, Francois Cury. Health Regulatory Focus, Selection Optimization and Compensation Strategy and Sports Practice: A Mediational Analysis. 2019. hal02274950

\author{
HAL Id: hal-02274950 \\ https://hal.science/hal-02274950
}

Preprint submitted on 30 Aug 2019

HAL is a multi-disciplinary open access archive for the deposit and dissemination of scientific research documents, whether they are published or not. The documents may come from teaching and research institutions in France or abroad, or from public or private research centers.
L'archive ouverte pluridisciplinaire HAL, est destinée au dépôt et à la diffusion de documents scientifiques de niveau recherche, publiés ou non, émanant des établissements d'enseignement et de recherche français ou étrangers, des laboratoires publics ou privés. 


\title{
$<$ AT > Health Focus, Selection Optimization and Compensation Strategy and Sports Practice: A Mediational Analysis
}

\author{
<AU> Manon Laroche ${ }^{1}$, Peggy Roussel ${ }^{1}$, Nicolas Mascret $^{1}$, and François Cury ${ }^{1,2}$ \\ <AFF1> Aix-Marseille Université (France) \\ $<\mathrm{AFF} 2>$ Université de Toulon (France)
}

$<\mathrm{COR}>$ Correspondence concerning this article should be addressed to Manon Laroche, Institut des Sciences du Mouvement, 163 Avenue de Luminy, CP 910, 13288 Marseille Cedex 9 (France). E-mail: manon.laroche@univ-amu.fr

\section{How to cite this article:}

Laroche, M., Roussel, P., Mascret, N., \& Cury, F. (2019). Heath focus, selection optimization and compensation strategy and sports practice: A mediational analysis. The Spanish Journal of Psychology, 22. Doi:XXXXXX 


\section{$<\mathrm{ABS}>$ Abstract}

This study aimed to investigate associations of health promotion and prevention regulatory foci with sports practice, and examined the Selection, Optimization and Compensation (SOC) process behind the positive relationship between health promotion focus and sports practice. A cross-sectional study was conducted with 513 French volunteer sports participants aged from 18 to 82. Participants completed an online self-report survey measuring health regulatory foci, SOC strategy, Amount of Sports Practice (ASP), health condition, and educational level. Path analysis main results $\left(\chi^{2}=16.64 ; d f=5 ; p<.01\right.$; RMSEA $=0.067$; CFI $\left.=0.98 ; R^{2}=.24\right)$ demonstrated that ASP was positively related with health promotion focus $(\beta$ $=.13, p<.01)$, SOC strategy $(\beta=.28, p<.001)$ and negatively related with health prevention focus $(\beta=-.20, p<.001)$. SOC strategy was positively related with health promotion focus $(\beta$ $=.39, p<.001)$ and bootstrapping analyses revealed that this strategy partially mediated the positive relationship between health promotion focus and ASP, 95\% CI [.13, .29]. Finally, additional analyses showed that it was specifically the elective selection, optimization and compensation sub-components of SOC strategy which played mediating roles in this link, [.13, $.29]<95 \% \mathrm{CI}<[.13, .29]$. For the first time in the literature, these results evidenced direct links between health regulatory foci and sports practice, and a mechanistic pathway between health promotion focus and sports practice. The theoretical and applied implications of these results for sports promotion are discussed.

<HIS> Received 22 March 2018; Revised XXXX; Accepted XXXX.

<KWD> Key words: health regulatory focus, SOC strategy, sports practice. 
Undertaking regular physical activity (PA) is one of the recommendations of public health information campaigns. Among the available forms of PA (e.g., those related to work, household or leisure), sport activity in their free time is one means that many individuals use to respond to these health messages. But each person responds in his or her own way, engaging in their preferred sport with greater or lesser amounts of practice. One of the most prominent factors determining individuals' participation in their sport is their motivation. Many motivational theories and models have brought real contributions to explain the antecedents and processes that give rise to sports practice (Ryan, 2012). In France, the motivations most often mentioned by adults who engage in sport are pleasure and health (Gleizes \& Pénicaud, 2017, November). The present study focuses on these health-related motivations, and the questions addressed are the following: What is the influence of health motivation on the amount of sports practice? What process can explain this influence?

Regulatory focus theory (Higgins, 1997), a well-established motivational theory and a useful framework in the health research area (Fuglestad, Rothman, \& Jeffery, 2008; Leder, Florack, \& Keller, 2015; Uskul, Keller, \& Oyserman, 2008), argues for the existence of two regulatory systems (promotion and prevention) which guide people in their self-care behaviors. Self-regulation with a promotion focus is associated with growth and accomplishment needs and is reflected in a concern for the presence or absence of positive outcomes (gains and nongains). Self-regulation with a prevention focus is associated with security and safety needs and is reflected in a concern for the presence or absence of negative outcomes (losses and nonlosses) (Higgins, 1997). In the literature, regulatory focus has been studied as a situationally induced orientation (e.g., experimentally manipulated by framing health communications, Cesario, Grant, \& Higgins, 2004) and as a chronic individual-difference variable assessed with dispositional measures (e.g., Higgins et al., 2001). To assess chronic regulatory focus, several studies in the health research area have used general measures of regulatory focus (e.g., Fuglestad et al., 2008; Joireman, Shaffer, Balliet, \& Strathman, 2012). Because the health domain involves specific situations that are not necessarily captured by general measures of regulatory focus, Gomez, Borges, \& Pechmann, 2013) and Ferrer et al. (2017) have recently highlighted the relevance of capturing chronic regulatory foci in the specific health context to study health behaviors. Chronic health regulatory foci measures have thus been developed. A chronic health promotion focus measure is supposed to capture concerns for improving the health state or attaining health-related gains. On the other hand, a chronic health prevention 
focus measure is supposed to capture concerns for protecting health state or avoiding healthrelated losses (Ferrer et al., 2017; Gomez et al., 2013). Gomez et al. (2013) examined the influence of these two chronic health regulatory foci on the adoption of several health behaviors such as health information seeking, consumption of organic and functional foods, number of physician and pharmacist visits or drug consumption. More recently, Ferrer et al. (2017) examined the influences of these two chronic health regulatory foci on intentions to perform several health behaviors including regular exercise.

The first aim of the present study was to extend Ferrer et al.'s (2017) study on regular exercise intention by examining for the first time in the literature the influences of chronic health promotion and prevention regulatory foci on the amount of sports practice. According to Rothman, Wlaschin, Bartels, Latimer and Salovey (2008), sports practice, balanced diet or sunscreen are among the health behaviors that promote health. These authors suggest that when people think about engaging in sport, they are more likely to attend to the presence or absence of favorable outcomes than to the presence or absence of unfavorable outcomes. Sports practice, being an activity that sustains a positive-outcomes approach could consequently fit better with a health promotion focus. One of the positive effects of fit is that people engage more strongly in what they are doing (Higgins, 2005). Thus, sports practice could be easier to undertake for people who experience a fit (Aaker \& Lee, 2006). Moreover, while sports practice can lead both to immediate (e.g., pleasure) or distal positive consequences (e.g., general health), Hall and Fong (2007) have nevertheless evidenced that this health behavior has the particularity of involving an intertemporal trade-off by accruing present costs to achieve delayed rewards. In particular, those authors examined the perceived temporal proximity of benefits associated with physical activity and show that benefits become salient the equivalent of several hundred hours later (2007, p. 11). Fuglestad et al. (2008) also suggested that engaging in a regular exercise program will probably entail a longer initiation phase to fully master the new, effortful behaviors and to achieve positive outcomes. Thus, the importance that individuals attach to the future consequences of their behavior influences their willingness to engage in this health behavior (e.g., Gellert, Ziegelmann, Lippke, \& Schwarzer, 2012). Promotion-focused individuals tend to adopt a distal temporal perspective whereas preventionfocused individuals tend to adopt a proximal temporal perspective (Pennington \& Roese, 2003). Joireman et al. (2012) also showed that a chronic general promotion focus was positively related to consideration of future consequences whereas a chronic general prevention 
focus tends to be positively related to consideration of immediate consequences. Thus, sports practice seems more in line with the distal temporal perspective of promotion-focused individuals. In addition, Ferrer et al.'s (2017) results evidenced that health promotion focus was positively related to the intention to exercise regularly whereas health prevention focus was negatively related to this variable. Based on these theoretical supports and Ferrer et al.'s (2017) empirical results, we thus expected that health promotion focus should be positively related with the amount of sports practice whereas health prevention focus should be negatively related with this variable.

Furthermore, while Ferrer et al.'s results (2017) support the idea that health promotion focus seems to be more favorable to physical activity, they do not inform us about the processes explaining this association. Thus, the second aim of this study was to explore for the first time in the literature a potential process behind the positive relationship expected between health promotion focus and sports practice. This process issue is important, both from a theoretical standpoint of acquiring, a clear and detailed understanding of how health promotion focus acts on sports practice, and from an applied standpoint of knowing how to support and facilitate sports practice. We proposed that the general set of resource allocation strategies SOC (Selection, Optimization and Compensation) could play a role in this process. Indeed, sports practice is a part of lifestyle behaviors which implies in individuals a self-management to overcome the perceived obstacles to practice (e. g., lack of time, family constraints, work Salmon, Owen, Crawford, Bauman, \& Sallis, 2003; Gómez-López, Granero Gallegos, \& Baena Extremera, 2010). Now, the SOC model (Baltes \& Baltes, 1990) evidences a set of four interrelated action regulation strategies that help individuals to self-manage in an optimal way: Elective selection (i.e., developing and committing to a hierarchy of personal goals), loss-based selection (i.e., changes in the goal or the goal system in response to loss), optimization (i.e., engaging in goal-directed actions and means), and compensation (i.e., acquiring alternative means or support in response to a loss). For Freund and Baltes (2002), SOC is "viewed as a coordinated ensemble of contextualized processes. Therefore, S, O, and $\mathrm{C}$ are considered conjointly and in their interaction for fully understanding their role in positive development" (p. 643). In the health domain, several studies have evidenced that use of SOC strategy has a positive influence on sports practice in a rehabilitation context (Ziegelmann \& Lippke, 2007), on maintenance of sports practice among older adults (Gellert, Ziegelmann, Krupka, Knoll, \& Schwarzer, 2014) and on long-term adherence to a sport program among older women (Evers, 
Klusmann, Ziegelmann, Schwarzer, \& Heuser, 2012). The adoption of sports practice involves an initial motivation process that results in intention formation and subsequent self-regulation processes that address the pursuit of these goals (Schwarzer, 1992). SOC strategy has been found to act as a mediator variable between planning (i.e., plans on 'when', 'where', and 'how' to perform a behavior) and exercise behavior (Ziegelmann \& Lippke, 2007). It is thus proposed that SOC strategy constitutes an important step in the process leading to sports practice.

Furthermore, SOC strategy calls for flexibility for development of new goals in response to difficulties, refinement of goal-relevant means, and acquisition of new skills/resources (Freund \& Baltes, 2002). Individuals with a promotion focus tend to approach desired end-states by engaging in flexible, explorative cognitive processing (Crowe \& Higgins, 1997). In addition, SOC is a strategy which serves a goal of achieving success (Baltes, Wynne, Sirabian, Krenn, \& de Lange, 2014), which is a goal congruent with promotion focus. Indeed, individuals with a promotion focus are attuned to emotions relating to the successful pursuit of positive outcomes (Higgins, Roney, Crowe, \& Hymes, 1994). Thus, promotion focus and SOC strategy are matching because they are goal-congruent. Finally, Baltes et al.'s (2014) results showed that a chronic general promotion focus was positively related to the adoption of SOC strategy at work. Based on these theoretical supports and Baltes et al.'s (2014) empirical results, we hypothesized thus that chronic health promotion focus should also be positively related to the adoption of SOC strategy in sport. Moreover, given the link expected on the one hand between health promotion focus and SOC strategy, and the link evidenced in the literature between SOC strategy and sports practice on the other hand, SOC strategy was hypothesized to mediate the positive relationship between health promotion focus and amount of sports practice.

In sum, the aims of the present study were twofold: (a) To explore the direct links between promotion and prevention health regulatory foci and amount of sports practice; and (b) to examine whether SOC strategy has a mediating role in the relationship between health promotion focus and amount of sports practice. These links will be examined among a large sample of sport practitioners. In addition, as age, gender, health condition and education level may affect physical activity practice (e.g., Shaw \& Spokane, 2008), the effects of these variables were controlled in the present study.

In accordance with the above-mentioned frameworks, we formulated the following hypotheses: 
Direct effects: Health promotion focus was expected to be positively related with amount of sports practice, whereas health prevention focus was expected to be negatively related with this variable.

Indirect effects: SOC strategy was expected to mediate the positive link between health promotion focus and amount of sports practice.

\section{$<\mathrm{H} 1>$ Method \\ $<\mathrm{H} 2>$ Participants}

To be eligible for the study, participants should practice a sport. A total of 588 French volunteer participants took part in the study. Of the initial 588 participants, 75 were excluded because of missing data. The responses of 513 participants (51.7\% men, $56.5 \%$ healthy) aged from 18 to 82 years (mean age $=36.96$, standard deviation $=16.33$, median score $=33$, skewness value $=.74$ ) were consequently considered in this study. Most of the participants $(97 \%)$ had completed secondary education. Demographic characteristics and health condition of the participants are presented in Table 1. All participants were recruited from various organizations, clubs and leisure centers and represented different sports, namely gym-based exercise (23\%), ball sports (21\%), racquet sports (17\%), running (14\%), walking (10\%), nature sports (6\%), swimming (3\%), cycling (2\%), fighting sports (2\%) and yoga (2\%). Furthermore, a high proportion of our sample had a relatively high level of sports practice in comparison with the amount of sports practice of the French population (European Commission, 2018): $50.7 \%$ of the participants practiced with high intensity, $91.6 \%$ practiced regularly, and $79.3 \%$ performed sports sessions for 60 minutes and more. The practice characteristics of the sample are presented in Table 2 .

\section{<Insert Table 1 Here > \\ < Insert Table 2 Here $>$}

\section{$<\mathrm{H} 2>$ Procedure}

Data were collected anonymously via a cross-sectional, online self-report survey. The protocol met France's ethical requirements for human research. Permission to conduct the study was first obtained from the administration. All participants provided informed consent prior to data collection.

\section{$<\mathrm{H} 2>$ Measures}

Health regulatory focus. Gomez et al.'s (2013) French health regulatory focus questionnaire was used to assess participants' health regulatory focus. The questionnaire is 
composed of five items assessing health promotion focus (e.g., "I do not hesitate to embrace new experiences if I think they can improve my health"), and three items assessing health prevention focus (e.g., "I frequently think about the health problems I may have in the future"), presented in a random order. Participants responded on a scale from $1=$ "not at all true of me" to $6=$ "very true for me". A Confirmatory Factor Analysis (CFA) was performed on the covariance matrix and the solution was generated by using maximum likelihood estimation. The two-factor model delineated by Gomez et al. (2013) did not provide an acceptable fit to the data $(\mathrm{RMSEA}=.101 ; \mathrm{GFI}=.947 ; \mathrm{CFI}=.935)$. The health prevention focus item (i.e., "When I implement a health behavior, it's because I want to protect myself from getting sick.") exhibited high modification indices as well as moderate loadings on both factors. These results were similar to those obtained by Schmalbach et al. (2017). In line with these authors' procedure, a model excluding this item was tested and showed an improvement over the model previously examined $(\mathrm{RMSEA}=.089 ; \mathrm{GFI}=.965 ; \mathrm{CFI}=.959)$. Internal consistency was satisfactory for both the health promotion focus $(\alpha=.78)$ and the two-item health prevention focus $(\alpha=.77)$ subscales. Average scores were thus computed for each health regulatory focus subscale.

SOC strategy. Ziegelmann and Lippke's (2007) questionnaire, a version of Freund and Baltes' (2002) original questionnaire adapted to the physical activity context, was used to assess participants' SOC strategy. The items were translated into French and slightly adjusted. The scale was composed of the stem "In general in my sport activity..." which was followed by three items assessing optimization strategy (e.g., “... I do everything possible to make my objectives come true"), and three items assessing elective selection strategy (e.g., "... I define my goals exactly and stick to them"). The second stem, "When it is getting more difficult in my sport activity...," was followed by three items assessing compensation strategy (e.g., "... then I increase my efforts even more to continue to practice my sport activity"), and three items assessing loss-based selection strategy (e.g., "... then I temporarily reduce the practice of my sport activity"). Participants responded on a scale from $1=$ "not at all true of $m e$ " to $6=$ "very true for me". A CFA was performed on the covariance matrix and the solution was generated by using maximum likelihood estimation. In line with Freund and Baltes (2002), who proposed the SOC model as an integrated system, a hierarchical model of SOC strategy was constructed comprising a higher-order factor (SOC strategy) and four first-order factors (loss-based Selection, elective Selection, Optimization and Compensation). The model provided an 
acceptable fit to the data (RMSEA $=.088$; GFI $=.927$; CFI $=.957)$ and internal consistency was satisfactory $(\alpha=.71)$. An average score was then computed for SOC strategy.

Amount of sports practice. Three items adapted from the sport and leisure activities subscale of the French Dijon Physical Activity Score (Robert et al., 2004) were used to assess amount of sports practice. This questionnaire is appropriate to assess usual sports practice in samples including elderly subjects aged up to 93 (Emile, Chalabaev, Stephan, Corrion, \& d'Arripe-Longueville, 2014). One item assessed sport activity intensity (i.e., "The sport activity that you practice is of: (3) High intensity: significant muscular fatigue, to (1) slight intensity: Without muscular fatigue"). One item assessed sport activity frequency (i.e., "You are used to practicing your sport activity: (4) Every day, to (1) irregularly"). One item assessed sport activity duration (i.e., "The average duration of your sessions for sport activity is: (4) 60 minutes and more, to (1) less than 15 minutes"). In line with Robert et al.'s (2004) procedure, the scores for the three items were added. The possible total score ranges vary between 3 (minimum) and 11 (maximum). The total score of sport and leisure activities subscale of this questionnaire has been shown to be reproductible in test-retest and to be correlated with peak VO2 and maximal power attained during effort test on a cycle ergometer and in walking tests (Gremeaux et al., 2008; Robert et al., 2004). The distribution of the sample on the scores of this measure is presented in Table 2.

Health condition. Consistent with prior research (e.g., Kempen, Jelicic, \& Ormel, 1997), a checklist of 18 diseases was used. Participants were asked to report whether they currently suffered from diseases diagnosed in the last 12 months. The total number of diseases diagnosed was used as a health condition index. The index ranged from 0 (none of the diseases) to 18 (all of the diseases).

Educational level. Participants indicated their highest educational qualification attained from 1 (no qualification) to $10(P h D)$.

\section{$<\mathrm{H} 2>$ Statistical analysis}

A model for evaluating the combined contribution (direct and indirect effects) of each variable - the promotion and prevention regulatory foci, SOC strategy, age, gender (coded as 0 for women and 1 for men), educational level and health condition - on amount of sports practice was tested. This model tested was built from our hypotheses. A covariance matrix, using Statistica- 12, was generated from raw data (observed scores in each variable). A path analysis using Lisrel 9.1 (Scientific Software International) was used to examine the fit of this 
first model. The .05 level of significance was used for all statistical hypothesis testing. Beta represents the standardized regression coefficient. We used the model fit tests using conservative cutoffs for root- mean- square error of approximation (RMSEA) and comparative fit index (CFI). Finally, a bootstrapping method resample (Preacher \& Hayes, 2008) was employed to test the significance of the mediation effect of SOC strategy on the relationship between health promotion focus and amount of sports practice. Bootstrapping was set at 5000 samples with bias-corrected $95 \%$ confidence intervals.

\section{$<\mathrm{H} 1>$ Results}

\section{$<\mathrm{H} 2>$ Descriptive statistics and correlations}

Means, standard deviations and Pearson's correlation coefficients for the variables are presented in Table 3. Furthermore, Khi-2 tests were conducted to examine gender differences. Only the amount of sports practice was impacted by gender. Men reported significantly higher amount of sports practice than women, $\chi^{2}(8)=45.67, p<.001$.

\section{<Insert Table 3 Here>}

\section{$<\mathrm{H} 2>$ Hypothesized model path analysis}

The results from the hypothesized model presented an acceptable fit $\left(\chi^{2}=36.15 ; d f=5\right.$; $p<.001 ;$ RMSEA $=0.110 ; \mathrm{CFI}=0.94)$. Considering the exploratory nature of this hypothesized model, a second model (adjusted model) was then tested including modification indices ${ }^{1}$ proposed by Lisrel. The second model tested, adjusted to the specific data, presented an excellent fit $\left(\chi^{2}=16.64 ; d f=5 ; p<.01\right.$; RMSEA $=0.067$; CFI $\left.=0.98\right)$. This model explained $24 \%$ of the variance of amount of sports practice. The results from the adjusted model, detailed below, are presented in Figure 1.

Direct effect. Amount of sports practice was positively related with health promotion focus $(\beta=.13, p<.01)$, SOC strategy $(\beta=.28, p<.001)$, and negatively related with health prevention focus $(\beta=-.20, p<.001){ }^{2}$ Moreover, amount of sports practice was positively

\footnotetext{
${ }^{1}$ In this adjusted model, a hypothetical path between age and SOC strategy was added, and the direct link between age and amount of sports practice was deleted. In accordance with Freund and Baltes (2002), we expected a negative association between age and SOC strategy, suggesting that age-related decline in resources and plasticity might limit the expression of this strategy.

${ }^{2}$ Analyses examining direct effect of health regulatory foci on amount of sports practice successively for three age groups of nearly equal subsample sizes (younger adults: 18-24 years, $N=174$; middleaged adults: $25-43$ years, $N=175$; older adults: $44-82, N=164$ ) confirmed globally the results obtained in the whole sample. The results confirmed the positive link between health promotion focus and amount of sports practice for younger and older age groups and indicated a nearly significant positive link for the middle age group. On the other hand, the results indicated a significant negative
} 
related with gender $(\beta=.28, p<.001)$, weakly negatively related with health condition variable $(\beta=-.08, p=.052)$, and not significantly related with educational level variable.

Indirect effect. SOC strategy was positively related with health promotion focus $(\beta=$ $.39, p<.001)$ and negatively related with age $(\beta=-.24, p<.001)$.

Bootstrapping analyses indicated that the indirect contribution of health promotion focus to amount of sports practice through SOC strategy was significant, with a point estimate of .040 and a bias-corrected bootstrapped $95 \%$ CI from .13 to .29. Therefore, since zero was not contained in the bootstrapped CI (see Preacher \& Hayes, 2008), SOC strategy may be considered a significant partial mediator of the relationship between health promotion focus and amount of sports practice, while controlling for educational level, gender and health condition. $^{3}$

\section{$<$ Insert Figure 1 Here > \\ <Insert Table 4 Here>}

\section{$<\mathrm{H} 2>$ Additional sub-components of SOC strategy path analyses}

As Freund and Baltes (2002) consider the SOC model an integrated system, the preceding analyses examined the composite score of SOC strategy as mediator of the link between health promotion focus and amount of sports practice. However, an existing empirical study suggests that specific strategies are more beneficial for exercise than others (Evers et al., 2012). Thus, it is possible that sub-components of SOC strategy are more or less involved in this process. This possibility was not the central interest in the present work, but an ancillary analysis was conducted to examine it. Four path models examining the mediating role of each of the four sub-components of SOC strategy in the positive link between health promotion focus and amount of sports practice were thus successively run. Age, ${ }^{4}$ gender, health condition and educational level effects were also controlled in these models. Results of these analyses

link between health prevention focus and amount of sports practice for the older group and nearly significant negative links for the younger and middle age groups (Table 4).

3 Analyses examining indirect effect successively for the three age groups confirmed that health promotion focus was indirectly associated with amount of sports practice through SOC strategy in the younger and middle age groups. However, they showed that for the older group, the indirect effect was not significant (Table 4).

${ }^{4}$ Concerning the age variable, the results, in line with Freund and Baltes (2002), indicated that age was negatively related with compensation. In addition, they showed that age was negatively related with optimization and elective selection and positively related with loss-based selection, whereas Freund and Baltes' (2002) results showed that age was not related with optimization, was positively related with elective selection, and tended to be positively related with loss-based selection. Thus, our results partially support those obtained by the authors, even if a comparison between the two studies must be undertaken with precaution, since the two studies did not use the same measures of SOC strategy. 
confirmed the mediating roles of elective selection, optimization and compensation in the positive link between health promotion focus and amount of sports practice. Specifically, elective selection and compensation partially mediated the link between health promotion focus and amount of sports practice, and optimization totally mediated this link. On the other hand, loss-based selection was not associated with health promotion focus and was negatively associated with amount of sports practice. Fit indices, beta coefficients and bootstrapped CI for each model are shown in Table 5.

\section{<Insert Table 5 Here>}

\section{$<\mathrm{H} 1>$ Discussion}

This study investigated the links between health promotion and prevention regulatory foci and amount of sports practice and examined a potential process that may account for the positive relationship between health promotion focus and amount of sports practice. Our findings provided strong support for our predictions. Firstly, in line with Ferrer et al.'s (2017) results based on intentions, our results indicated that health promotion focus was positively related to amount of sports practice whereas health prevention focus was negatively related to this variable. Analyses conducted in sub-groups of participants indicated that these links were globally consistent across age. Ferrer et al. (2017) have hypothesized that prevention focus could be associated "with less willingness to engage in any behavior, which would explain why it predicted both lower healthy intentions here, and lower risky intentions in previous work" (p. 54). Our results evidence that as regards self-reported amount of sports practice (and not intention), health prevention focus is also negatively related to this variable. Our results thus provide additional evidence that sports practice is a health behavior positively related to health promotion focus and negatively with health prevention focus. These results could be attributed to the fact that, in contrast to other health behaviors whose primary function is to protect individuals against potential health threats - e.g., screening procedures (Ferrer et al., 2017), vaccination (Leder et al., 2015), use of drugs (Gomez et al., 2013) - physical activity is part of health behaviors whose primary function is the attainment of positive health outcomes (Rothman et al., 2008). This behavior consequently fits better with a health promotion focus than a health prevention focus.

The second aim of this study was to examine a process through which health promotion focus is positively linked with sports practice, an issue that has received no attention in the literature. As hypothesized, our main findings indicated that health promotion focus was 
positively related to SOC strategy considered as a coordinated ensemble of processes. These first findings were consistent with Baltes et al.'s (2014) result evidenced in a work-related context. It supports the idea that promotion focus generates in individuals a flexible strategic tendency (Crowe \& Higgins, 1997) and a concern for achieving success (Higgins et al., 1994) emphasized by SOC strategy. In addition, these results indicated that SOC strategy partially mediated the positive relation between health promotion focus and amount of sports practice This mediational finding provides for the first time in the literature an explanation of how the direct positive link between health promotion focus and amount of sports practice occurs. However, additional sub-components of SOC strategy path analyses showed that when the four SOC strategies are examined separately, only three of them (i.e., elective selection, optimization and compensation) played mediating roles. Concerning loss-based selection, the results showed first that this strategy was not related with health promotion focus. Secondly, in line with Evers et al.'s (2012) research, the results showed that this strategy was negatively associated with amount of sports practice. It seems that this strategy, which consists in changing the goal or the goal system in response to loss (Baltes \& Baltes, 1990), is compatible neither with the concern of health promotion focus centered on achieving success nor with the usual amount of sports practice. Further research is needed to explore these issues.

Although the findings of the present study provide greater insights into (a) the direct links between health regulatory foci and sports practice, and (b) a mechanistic pathway between health promotion focus and sports practice, there are some limitations. First, our study focused on the determinants favorable to sports practice and was therefore quite naturally oriented toward analysis of the positive dynamic linked to health promotion focus. The negative link between health prevention focus and amount of sports practice also requires further study. Additional research is needed to investigate the potential processes through which health prevention focus is negatively related to sports practice. For example, one could start from the fact that the prevention focus tends to be positively associated with immediate consequences of behavior which is negatively associated with exercise attitude and intention (Joireman et al., 2012). Thus, immediate future consequences of behaviors (Strathman, Gleicher, Boninger, \& Edwards, 1994) could be a plausible candidate contributing to mediate the negative relationship between health prevention focus and sports practice. Secondly, our study was interested in the relationship between health regulatory foci and amount of sports practice considered as a health behavior integrated into our participants' lifestyles. Fuglestad et 
al., (2008) have shown that the relationship between regulatory foci and other health behaviors (i.e., smoking cessation, weight loss) were moderated by the different phases of behavioral change. They showed that promotion-focused individuals were more likely to initiate smoking cessation and weight loss, and that prevention-focused individuals were more likely to maintain these behaviors longer. Based on these works, it would be interesting to examine in a future study the moderating effect of length of time of practice (i.e., beginners vs long-term practitioners) on the links between health regulatory foci and amount of sports practice. Thirdly, the cross-sectional design of the present study does not allow for causal claims among the variables. Experimental manipulation of the health regulatory focus to determine the effects on sports practice and SOC strategy would be of great value. Also, the specificity of our sample (i.e., highly educated participants, high levels of sports practice) limits the generalization of our results. Further study could extend these results to other populations. Finally, while our results show the predictive value of health regulatory foci on the amount of sport habitually practiced by the participants, other motivations of practice (e.g., fun, fitness, competition, making friends, etc. - see Ryan, Frederick, Lepes, Rubio, \& Sheldon, 1997) could broaden the scope of our observations. A further study examining to what extent health regulatory foci are related to amount of sports practice by controlling the weight of other sports motives could be very interesting and would complement our present results.

Beyond these limitations, our findings contribute to the literature in health psychology by evidencing for the first time links between health regulatory foci and sports practice, and a specific process underlying the link between health promotion focus and this behavior. In addition to these theoretical implications, our study also suggests practical steps. To make communications recommending sports practice more effective and to promote this health behavior, it is preferable to stress the improvement of health (promotion argument) rather than the avoidance of disease (prevention argument). The positive dynamic associated with promotion inspires practitioners' capacities to organize and manage themselves to cope with the specific constraints of sports practice. So, whether in large-scale public health campaigns (mass communication), in the discussions that doctors and sports educators may have with people or in support for practitioners through health apps and sports coaching, messages and arguments on the sport-health theme should highlight the health gains and benefits that can be achieved. It remains to be verified, however, how effective such communication is on the 
amount of sports practice depending on the length of time a person has engaged in sports activity. 


\section{$<\mathrm{H} 1>$ References}

$<$ REFJ> Aaker, J. L., \& Lee, A. Y. (2006). Understanding regulatory fit. Journal of Marketing Research, 43(1), 15-19. http://doi.org/10.1509/jmkr.43.1.15

<REFJ> Baltes, P. B., \& Baltes, M. M. (1990). Psychological perspectives on successful aging: The model of selective optimization with compensation. In P. B. Baltes \& M. M. Baltes (Eds.), Successful aging: Perspectives from the behavioral sciences (pp. 1-34). New York, NY: Cambridge University Press.

<REFJ> Baltes, B. B., Wynne, K., Sirabian, M., Krenn, D., \& de Lange, A. (2014). Future time perspective, regulatory focus, and selection, optimization, and compensation: Testing a longitudinal model. Journal of Organizational Behavior, 35(8), 1120-1133. http://doi.org/10.1002/job.1970

$<$ REFJ > Cesario, J., Grant, H., \& Higgins, E. T. (2004). Regulatory fit and persuasion: Transfer from "feeling right". Journal of Personality and Social Psychology, 86(3), 388-404. http://doi.org/10.1037/0022-3514.86.3.388

$<$ REFJ> Crowe, E., \& Higgins, E. T. (1997). Regulatory focus and strategic inclinations: Promotion and prevention in decision-making. Organizational Behavior and Human Decision Processes, 69(2), 117-132. http://doi.org/10.1006/obhd.1996.2675

$<$ REFJ > Emile, M., Chalabaev, A., Stephan, Y., Corrion, K., \& d'Arripe-Longueville, F. (2014). Aging stereotypes and active lifestyle: Personal correlates of stereotype internalization and relationships with level of physical activity among older adults. Psychology of Sport and Exercise, 15(2), 198-204. http://doi.org/10.1016/j.psychsport.2013.11.002

$<$ REFJ $>$ European Commission (2018). Sport and physical activity (Report No. 472). Retrieved from European Commission website: http:// sante.public.lu/fr/publications/s/sport-activitesphysiques-en-2014

$<$ REFJ> Evers, A., Klusmann, V., Ziegelmann, J. P., Schwarzer, R., \& Heuser, I. (2012). Long-term adherence to a physical activity intervention: The role of telephone-assisted vs. selfadministered coping plans and strategy use. Psychology \& Health, 27(7), 784-797. http://doi.org/10.1080/08870446.2011.582114

$<$ REFJ> Ferrer, R. A., Lipkus, I. M., Cerully, J. L., McBride, C. M., Shepperd, J. A., \& Klein, W. M. P. (2017). Developing a scale to assess health regulatory focus. Social Science \& Medicine, 195, 50-60. http://doi.org/10.1016/j.socscimed.2017.10.029

$<$ REFJ $>$ Freund, A. M., \& Baltes, P. B. (2002). Life-management strategies of selection, optimization and compensation: Measurement by self-report and construct validity. Journal of Personality and Social Psychology, 82(4), 642-662. http://doi.org/10.1037/0022-3514.82.4.642

$<$ REFJ > Fuglestad, P. T., Rothman, A. J., \& Jeffery, R. W. (2008). Getting there and hanging on: The effect of regulatory focus on performance in smoking and weight loss interventions [Special issue]. Health Psychology, 27(3), S260-S270. http://doi.org/10.1037/02786133.27.3(Suppl.).S260

<REFJ> Gellert, P., Ziegelmann, J. P., Krupka, S., Knoll, N., \& Schwarzer, R. (2014). An age-tailored intervention sustains physical activity changes in older adults: A randomized controlled trial. International Journal of Behavioral Medicine, 21(3), 519-528. http://dx.doi.org/10.1007/s12529-013-9330-1

$\langle$ REFJ $>$ Gellert, P., Ziegelmann, J. P., Lippke, S., \& Schwarzer, R. (2012). Future time perspective and health behaviors: Temporal framing of self-regulatory processes in physical exercise and dietary behaviors. Annals of Behavioral Medicine, 43(2), 208-218. http://doi.org/10.1007/s12160-0119312-y

$<$ REFJ > Gleizes, F., \& Pénicaud, É. (2017, November). Pratiques physiques ou sportives des femmes et des hommes: Des rapprochements mais aussi des différences qui persistent [Physical and sporting practices of women and men: Similarities but also differences that persist]. Insee Première, 1675. Retrieved from https://www.insee.fr/fr/statistiques/3202943

$<$ REFJ > Gomez, P., Borges, A., \& Pechmann, C. C. (2013). Avoiding poor health or approaching good health: Does it matter? Conceptualization, measurement and consequences of health regulatory 
focus. Journal of Consumer Psychology, 23(4), 451-463. h

http://dx.doi.org/10.1016/j.jcps.2013.02.001

<REFJ> Gómez-López, M., Granero Gallegos, A., \& Baena Extremera, A. (2010). Perceived barriers by university students in the practice of physical activities. Journal of Sports Science \& Medicine, 9(3), 374-381.

$<$ REFJ> Gremeaux, V., Lemoine, Y., Fargeot, A., D’Athis, P., Beer, J.-C., Laurent, Y., ... Casillas, J.M. (2008). Le score d'activité physique de Dijon: Reproductibilité et corrélations avec l'aptitude physique de sujets coronariens [The Dijon Physical Activity Score: Reproducibility and correlations with physical fitness in patients with coronary artery disease]. Annales de Réadaptation et de Médecine Physique, 51(5), 366-378. http://doi.org/10.1016/j.annrmp.2008.05.003

$<$ REFJ> Hall, P. A., \& Fong, G. T. (2007). Temporal self-regulation theory: A model for individual health behavior. Health Psychology Review, 1(1), 6-52. http://doi.org/10.1080/17437190701492437

$<$ REFJ> Higgins, E. T. (1997). Beyond pleasure and pain. American Psychologist, 52(12), 1280-1300. http://doi.org/10.1037/0003-066X.52.12.1280

$<$ REFJ> Higgins, E. T. (2005). Value from regulatory fit. Current Directions in Psychological Science, 14(4), 209-213. http://doi.org/10.1111/j.0963-7214.2005.00366.x

<REFJ> Higgins, E. T., Friedman, R. S., Harlow, R. E., Idson, L. C., Ayduk, O. N., \& Taylor, A. (2001). Achievement orientations from subjective histories of success: Promotion pride versus prevention pride. European Journal of Social Psychology, 31(1), 3-23. http://doi.org/10.1002/ejsp.27

$<$ REFJ > Higgins, E. T., Roney, C. J., Crowe, E., \& Hymes, C. (1994). Ideal versus ought predilections for approach and avoidance distinct self-regulatory systems. Journal of Personality and Social Psychology, 66(2), 276-286. http://dx.doi.org/10.1037/0022-3514.66.2.276

$<$ REFJ > Joireman, J., Shaffer, M. J., Balliet, D., \& Strathman, A. (2012). Promotion orientation explains why future-oriented people exercise and eat healthy: Evidence from the two-factor consideration of future consequences-14 scale. Personality and Social Psychology Bulletin, 38(10), 1272-1287. http://doi.org/10.1177/0146167212449362

<REFJ> Kempen, G. I., Jelicic, M., \& Ormel, J. (1997). Personality, chronic medical morbidity, and health-related quality of life among older persons. Health Psychology, 16(6), 539-546. http://doi.org/10.1037/0278-6133.16.6.539

$<$ REFJ> Leder, S., Florack, A., \& Keller, J. (2015). Self-regulation and protective health behavior: How regulatory focus and anticipated regret are related to vaccination decisions. Psychology and Health, 30(2), 165-188. http://doi.org/10.1080/08870446.2014.954574

$<$ REFJ > Pennington, G. L., \& Roese, N. J. (2003). Regulatory focus and temporal distance. Journal of Experimental Social Psychology, 39(6), 563-576. http://doi.org/10.1016/S0022-1031(03)000581

$<$ REFJ> Preacher, K. J., \& Hayes, A. F. (2008). Asymptotic and resampling strategies for assessing and comparing indirect effects in multiple mediator models. Behavior Research Methods, 40(3), 879-891. http://doi.org/10.3758/BRM.40.3.879

<REFJ> Robert, H., Casillas, J. M., Iskandar, M., D’Athis, P., Antoine, D., Taha, S., ... van Hoecke, J. (2004). Le score d'activité physique de Dijon: Reproductibilité et corrélations avec l'aptitude physique de sujets sains âgés [The Dijon Physical Activity Score: Reproducibility and correlation with exercise testing in healthy elderly subjects]. Annales de Réadaptation et de Médecine Physique, 47(8), 546-554. http://doi.org/10.1016/j.annrmp.2004.03.005

$<$ REFJ > Rothman, A. J., Wlaschin, J., Bartels, R. D., Latimer, A., \& Salovey, P. (2008). How persons and situations regulate message framing effects: The study of health behavior. In A. J. Elliot (Ed.), Handbook of approach and avoidance motivation (pp. 475-486). Mahwah, NJ: LEA.

<REFJ> Ryan, R. M. (2012). The Oxford handbook of human motivation. New York, NY: Oxford University Press.

<REFJ> Ryan, R. M., Frederick, C. M., Lepes, D., Rubio, N., \& Sheldon, K. M. (1997). Intrinsic motivation and exercise adherence. International Journal of Sport Psychology, 28(4), 335-354. 
$<$ REFJ > Salmon, J., Owen, N., Crawford, D., Bauman, A., \& Sallis, J. F. (2003). Physical activity and sedentary behavior: A population-based study of barriers, enjoyment, and preference. Health Psychology, 22(2), 178-188. http://doi.org/10.1037/0278-6133.22.2.178

<REFJ> Schmalbach, B., Spina, R., Steffens-Guerra, I., Franke, G. H., Kliem, S., Michaelides, M. P., ... Zenger, M. (2017). Psychometric properties of the German version of the Health Regulatory Focus scale. Frontiers in Psychology, 8, 2005. http://doi.org/10.3389/fpsyg.2017.02005

<REFJ> Schwarzer, R. (1992). Self-efficacy in the adoption and maintenance of health behaviors: Theoretical approaches and a new model. In R. Schwarzer (Ed.), Self-efficacy: Thought control of action (pp. 217-243). Washington, DC: Hemisphere.

$<$ REFJ > Shaw, B. A., \& Spokane, L. S. (2008). Examining the association between education level and physical activity changes during early old age. Journal of Aging and Health, 20(7), 767-787. http://doi.org/10.1177/0898264308321081

$<$ REFJ > Strathman, A., Gleicher, F., Boninger, D. S., \& Edwards, C. S. (1994). The consideration of future consequences: Weighing immediate and distant outcomes of behavior. Journal of Personality and Social Psychology, 66(4), 742-752. http://doi.org/10.1037/0022-3514.66.4.742

$<$ REFJ > Uskul, A. K., Keller, J., \& Oyserman, D. (2008). Regulatory fit and health behavior. Psychology \& Health, 23(3), 327-346. http://doi.org/10.1080/14768320701360385

<REFJ> Ziegelmann, J. P., \& Lippke, S. (2007). Planning and strategy use in health behavior change: A life span view. International Journal of Behavioral Medicine, 14(1), 30-39.

http://dx.doi.org/10.1007/BF02999225 


\section{Table 1.}

Demographic Characteristics and Health Condition of the Sample

\begin{tabular}{|c|c|c|}
\hline & $N$ & $\%$ \\
\hline \multicolumn{3}{|l|}{ Gender } \\
\hline Men & 265 & 51.7 \\
\hline Women & 248 & 48.3 \\
\hline \multicolumn{3}{|l|}{ Age distribution } \\
\hline Young (18-24) & 174 & 33.9 \\
\hline Middle (25-43) & 175 & 34.1 \\
\hline Old (44-82) & 164 & 32 \\
\hline \multicolumn{3}{|l|}{ Health condition } \\
\hline Healthy & 290 & 56.5 \\
\hline Unhealthy & 223 & 43.5 \\
\hline Chronic joint or back problems & 96 & 18.7 \\
\hline Asthma or chronic bronchitis & 67 & 13.1 \\
\hline Arthritis & 38 & 7 \\
\hline Migraine or chronic headache & 32 & 6.2 \\
\hline Hypertension & 32 & 6.2 \\
\hline Serious dermatological disorders & 25 & 4.9 \\
\hline Diabetes & 15 & 2.9 \\
\hline Chronic heart disease & 13 & 2.5 \\
\hline Kidney disease & 13 & 2.5 \\
\hline Cancer & 10 & 1.9 \\
\hline Liver disorder or gallstones & 10 & 1.9 \\
\hline Thyroid and gland disorders & 8 & 1.6 \\
\hline Stroke & 4 & 0.8 \\
\hline Stomach ulcer & 4 & 0.8 \\
\hline Leg ulcer & 3 & 0.6 \\
\hline Epilepsy & 1 & 0.2 \\
\hline Pulmonary emphysema & 0 & 0 \\
\hline Sclerosis & 0 & 0 \\
\hline \multicolumn{3}{|l|}{ Educational level } \\
\hline Primary school or lower & 16 & 3.1 \\
\hline Middle school & 29 & 5.7 \\
\hline High school & 136 & 26.5 \\
\hline University & 332 & 64.7 \\
\hline
\end{tabular}


Table 2.

Practice Characteristics of the Sample

\begin{tabular}{lcc}
\hline Intensity of sports practice & $N$ & $\%$ \\
High (significant muscle fatigue) & & \\
Moderate (moderate muscle fatigue) & 260 & 50.7 \\
Low (without muscle fatigue) & 148 & 28.8 \\
& 105 & 20.5 \\
Frequency of sports practice & & \\
Every day & 38 & 7.4 \\
3 to 6 times per week & 162 & 31.6 \\
1 to 2 times per week & 270 & 53 \\
Irregularly & 43 & 8.4 \\
& & \\
Duration of sports practice & & \\
60 minutes and more & 407 & 79.3 \\
30 to 60 minutes & 94 & 18.3 \\
15 to 30 minutes & 8 & 1.6 \\
less than 15 minutes & 4 & 0.8
\end{tabular}

Total score of amount of sports practice

Score values

9 to 11

$285 \quad 55.6$

6 to 8

$216 \quad 42.1$

3 to 5

$12 \quad 2.3$

Note. Total score of amount of sports practice is the sum of scores of intensity (from 3 = high intensity to $1=$ slight intensity), frequency (from $4=$ every day to 1 $=$ irregularly) and duration (from $4=60$ minutes and more to $1=$ less than 15 minutes). 
Table 3.

Descriptive Statistics and Matrix of Pearson r Correlation Coefficients among the Variables $(N=513)$.

\begin{tabular}{|c|c|c|c|c|c|c|c|c|c|}
\hline & $M$ & $S D$ & 1 & 2 & 3 & 4 & 5 & 6 & 7 \\
\hline 1. Health promotion focus & 4.11 & 0.91 & - & & & & & & \\
\hline 2. Health prevention focus & 3.73 & 1.37 & $.23 * *$ & - & & & & & \\
\hline 3. SOC strategy & 3.98 & 0.62 & $.39 * *$ & .01 & - & & & & \\
\hline 4. ASP & 8.44 & 1.42 & $.13^{* *}$ & $-.19 * *$ & $.36^{* *}$ & - & & & \\
\hline 5. Age & 36.96 & 16.33 & $.14 * *$ & $.26 * *$ & $-.19^{* *}$ & $-.24 * *$ & - & & \\
\hline 6. Educational level & 6.42 & 1.87 & .06 & -.05 & .04 & .05 & .03 & - & \\
\hline 7. Health condition & 0.71 & 1.06 & $-.09 *$ & $.24 * *$ & $-.17 * *$ & $-.18 * *$ & $.42 * *$ & $-.17 * *$ & - \\
\hline
\end{tabular}


Summary of the Fit and Pathways of Hypothetical Model of ASP for each Age Group

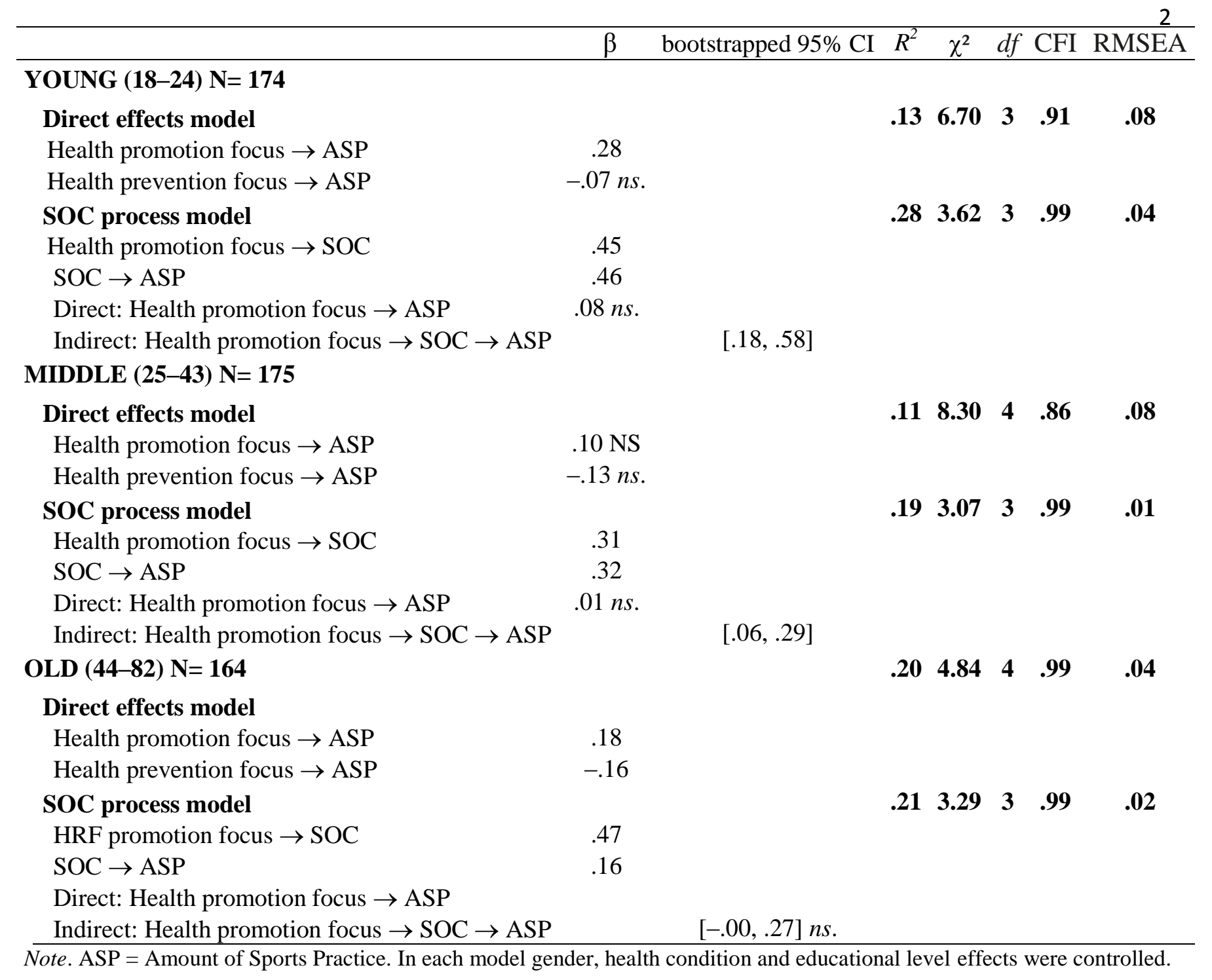


Table 5.

Summary of the Fit and Pathways of Models of ASP for each Sub Component of SOC

\begin{tabular}{|c|c|c|c|c|c|c|c|}
\hline & $\beta$ & bootstrapped $95 \% \mathrm{CI}$ & $R^{2}$ & $\chi^{2}$ & $d f$ & CFI & RMSEA \\
\hline Elective Selection (ES) process model & & & .20 & 8.81 & 4 & .99 & .05 \\
\hline Age $\rightarrow$ ES & -.20 & & & & & & \\
\hline Health promotion focus $\rightarrow$ ES & .34 & & & & & & \\
\hline $\mathrm{ES} \rightarrow \mathrm{ASP}$ & .22 & & & & & & \\
\hline Direct: Health promotion focus $\rightarrow$ ASP & .14 & & & & & & \\
\hline Indirect: Health promotion focus $\rightarrow \mathrm{ES} \rightarrow \mathrm{ASP}$ & & {$[.06 ; .19]$} & & & & & \\
\hline Loss-Based Selection (LBS) process model & & & .19 & 12.35 & 4 & .98 & .06 \\
\hline Age $\rightarrow$ LBS & .20 & & & & & & \\
\hline Health promotion focus $\rightarrow$ LBS & $-.01 n s$. & & & & & & \\
\hline $\mathrm{LBS} \rightarrow \mathrm{ASP}$ & -.21 & & & & & & \\
\hline Direct: Health promotion focus $\rightarrow$ ASP & .20 & & & & & & \\
\hline Indirect: Health promotion focus $\rightarrow$ LBS $\rightarrow$ ASP & & {$[-.03 ; .04] n s$. } & & & & & \\
\hline Optimization (Opt) process model & & & .23 & 10.96 & 4 & .99 & .06 \\
\hline Age $\rightarrow$ Opt & -.34 & & & & & & \\
\hline Health promotion focus $\rightarrow$ Opt & .40 & & & & & & \\
\hline $\mathrm{Opt} \rightarrow \mathrm{ASP}$ & .33 & & & & & & \\
\hline Direct: Health promotion focus $\rightarrow$ ASP & $.07 n s$. & & & & & & \\
\hline Indirect: Health promotion focus $\rightarrow \mathrm{Opt} \rightarrow$ ASP & & {$[.15 ; .32]$} & & & & & \\
\hline Compensation (Comp) process model & & & .28 & 7.62 & 4 & .99 & .04 \\
\hline Age $\rightarrow$ Comp & -26 & & & & & & \\
\hline Health promotion focus $\rightarrow$ Comp & .28 & & & & & & \\
\hline Comp $\rightarrow$ ASP & .39 & & & & & & \\
\hline Direct: Health promotion focus $\rightarrow$ ASP & .09 & & & & & & \\
\hline Indirect: Health promotion focus $\rightarrow$ Comp $\rightarrow$ ASP & & {$[.12 ; .26]$} & & & & & \\
\hline
\end{tabular}

Note: ASP $=$ Amount of Sports Practice. In each model gender, educational level and health condition effects were controlled. 


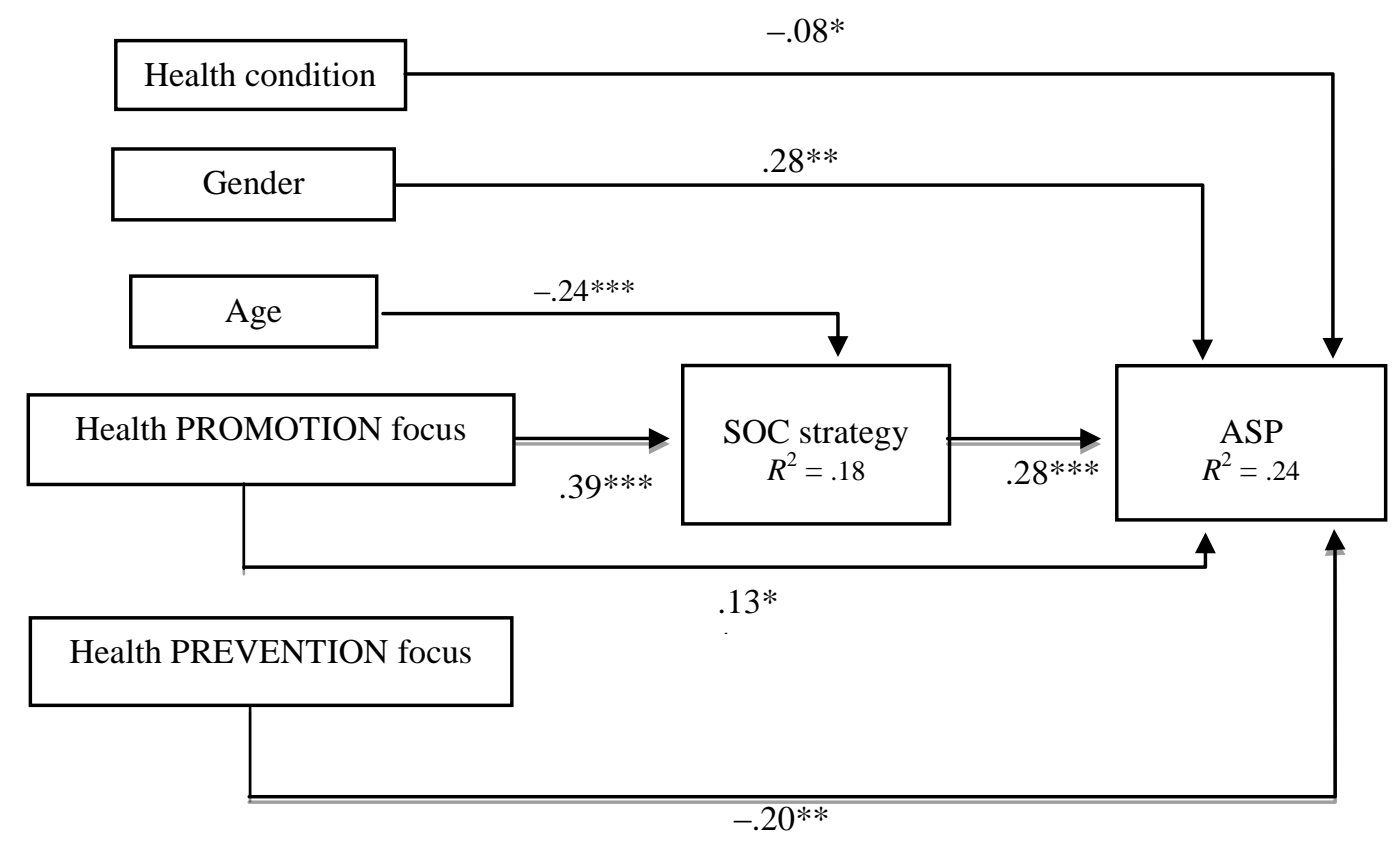

Figure 1. Path Diagram of Adjusted Model

Figure 1. ASP $=$ Amount of Sports Practice. Standardized path coefficients are presented. Nonsignificant paths are not included in the figure.

$* p=.05 . * * p<.01 . * * * p<.001$. 